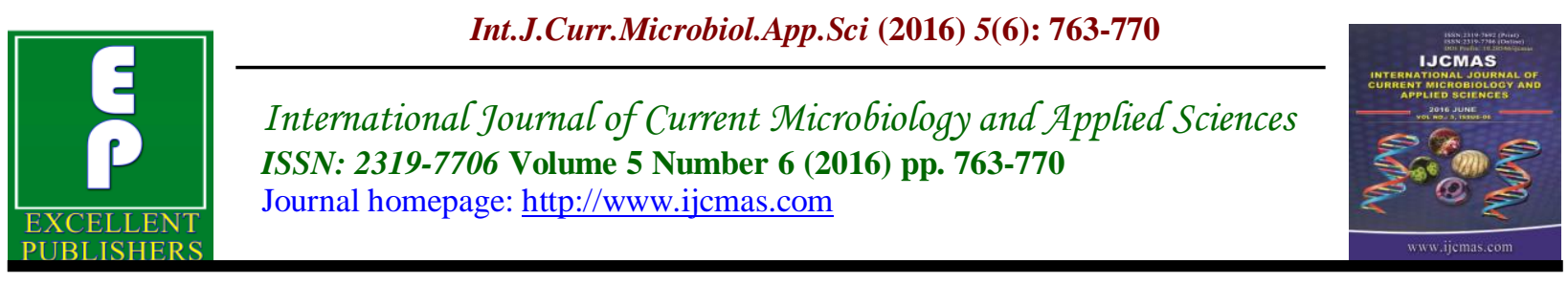

Original Research Article

http://dx.doi.org/10.20546/ijcmas.2016.506.084

\title{
Incidence and Comparative Awareness regarding Needle Stick Injuries among Health Care Workers: A Tertiary Healthcare based Study from North India
}

\author{
M. Debbarma*, S. Gogoi, M. Jais, P.Gupta, P. Sharma and R. Kaur \\ Lady Hardinge Medical College, New Delhi-110001, India \\ *Corresponding author
}

\begin{abstract}
A B S T R A C T
Needle stick Injuries (NSIs) are one of the most potential hazards for Heath Care Workers (HCWs) which put them at risk of acquiring blood borne pathogens such as hepatitis B, C and HIV. This study aims to estimate the incidence along with the

Keywords

Awareness,

Health care workers (HCW), needle stick injury (NSI), post exposure prophylaxis (PPE).

\section{Article Info}

Accepted:

25 May 2016

Available Online:

10 June 2016 awareness regarding NSIs, among the health care workers of Lady Hardinge Medical College \& Associated Hospitals. The present study was a cross sectional study conducted for a period of one year and three months among $400 \mathrm{HCWs}$. A self structured pretested questionnaire was used as a tool in the study. The level of awareness was graded (adequate, fairly adequate and inadequate) on the basis of their knowledge. A score of more than $70 \%$ was considered adequate awareness, $50-70 \%$ fairly adequate awareness, and less than $50 \%$ was taken as inadequate awareness. Awareness level regarding NSI was adequate among 38.8\% doctors, 23 $\%$ nurses and $8 \%$ technicians. Eighteen percent (18.4\%) doctors, 9\% nurses and 4\% technicians had adequate awareness level regarding PEP. The difference between adequate awareness level regarding NSI and post exposure prophylaxis (PEP) among different groups of HCWs was significant $(\mathrm{P}<0.05)$. Incidence rate of NSI among HCWs is $41.5 \%$ but only $11.8 \%$ were reported. The mean of $\mathrm{NSI} / \mathrm{HCW} / \mathrm{year}$ is highest (0.81) in nurses followed by doctors (0.67) and followed by technicians (0.66). The Obstetrics \& Gynaecology department had highest (mean $=0.93)$ number of NSI followed by pediatrics $(0.74)$ and surgery $(0.68)$. The present study shows that the reporting of NSI is poor. So regular training programs are needed to raise the awareness level and reporting regarding NSI.
\end{abstract}

\section{Introduction}

Needle stick injuries (NSIs) are wounds caused by sharps such as hypodermic needles, blood collection needles, intravenous (i.v) cannulas or needles used to connect part of i.v delivery systems. (Muralidhar et al., 2010) It is one of the greatest risks faced by the frontline health care worker exposing them to dangerous and deadly blood borne pathogens such as HIV, Hepatitis B \& C. Considering the importance of the NSI. The Needle stick Safety and Prevention Act was signed into law in November 2000 and became effective in April 2001. (Kotwal, 2010; Foley et al., 2003) Not following the standard precautions strictly by the HCWs, is the 
major cause of NSI. The various other factors implicated in NSI are type and design of needle, recapping activity, handling/ transferring the needles, collision between HCWs or sharps, during clean- up, manipulating needles in patient line related work and failure to dispose of needle in puncture proof containers. The center for Disease control and prevention (CDC) estimates that about 3,85,000 sharp injuries occur annually among HCWs in hospitals around the world. (Centers for Disease Control and prevention, 2015) The average risk of transmission of HIV, Hepatitis B, Hepatitis $\mathrm{C}$ to a $\mathrm{HCW}$ after percutaneous exposure is 0.1 to $0.3 \%, 10$ to $30 \%, 3$ to $10 \%$ respectively. The incidence of NSIs is considerably higher than the current estimates, due to gross underreporting (often less than $50 \%$ ). So a low injury rate should not be interpreted as a less serious issue (Camilla Rodrigues, 2010).

With this background the present study was conducted among the HCWs of Lady Hardinge Medical College and associated hospitals (SSKH \& KSCH), New Delhi, with the following objectives, to assess the awareness towards Needle stick injury among HCWs. to estimate the incidence of needle stick injury among the HCWs. And also evaluate and analyze various factors related to NSI.

\section{Materials and Methods}

The present study was a cross sectional study conducted for a period of one year and three months among 400 HCWs which included 250 doctors, 100 nursing professionals, 50 laboratory technicians of LHMC and associated hospitals. These 400 HCWs included in the study were from various departments of LHMC \& Associated Hospitals such as Medicine, Surgery, Obstetrics \& Gynaecology, Pediatrics,
Orthopedics, Ophthalmology, ENT, Pathology, Microbiology, Biochemistry, Anesthesia, Community Medicine and psychiatry.

A self structured pretested questionnaire consisting of 11 multiple choice questions was used as a tool to access HCWs awareness regarding NSI. The initial part of the questionnaire was having demographic information of the participant such as occupation, age, sex, work experience and current posting, whereas rest were the questions related to NSI . Various Departments (as mentioned above) of LHMC \& Associated Hospitals were visited on rotational basis and HCWs who gave voluntary consent for participation in the study were given 15 minutes each to answer the questionnaire in an independent and unbiased way without any undue pressure, maintaining the confidentiality of their identity.

The data obtained from the questionnaires was evaluated by giving 1 point for each correct answer given by the participants. There was no negative marking for wrong answers.. The level of awareness was graded (adequate, fairly adequate and inadequate) on the basis of their knowledge regarding a particular practices. A score of more than $70 \%$ was considered adequate awareness, 50-70\% fairly adequate awareness, and less than $50 \%$ was taken as inadequate awareness.

Finally, HCWs were considered to be aware of a particular practice, when the overall awareness (i.e. adequate+ fairly adequate) was more than $50 \%$. Finally, HCWs are considered to be aware of a particular practice, when the overall awareness (i.e. adequate+ fairly adequate) is more than $50 \%$. 


\section{Statistical Analysis}

Data obtained from the questionnaires was analyzed by using SPSS software. Descriptive statistics was used to calculate percentages for each of the responses given. Chi-square test for comparing percentages across groups, ANOVA for comparing means across more than 2 groups and Unpaired t-test for comparing more than 2 groups. A P value less than 0.05 was considered significant.

\section{Results and Discussion}

Out of 250 doctors, 100 nurses and 50 laboratory technicians (Total HCW 400) included in the present study, $23.2 \%$ were male and $76.7 \%$ HCWs were female. Majority $(60.25 \%)$ of the study population belonged to the age group of 20-30 yrs (mean age 30.72 yrs). Most (23.5\%) of HCWs were from Department of Obstetrics $\&$ gynecology followed by Surgery $(15 \%)$ and medicine ( $14.75 \%$ ) department.

Awareness level was adequate regarding NSI among $38.8 \%$ doctors, $23 \%$ nurses and $8 \%$ technicians. Fairly adequate level of awareness was $56.4 \%, 63 \%$ and $70 \%$ among doctors, nurses and technicians respectively. Five percent $(4.8 \%)$ doctors, $14 \%$ nurses and $22 \%$ technicians were found to have inadequate awareness level regarding NSI. The difference between adequate awareness level among the different groups were significant $(\mathrm{p}<0.05)($ Table $: 1)$

Eighteen percent (18.4\%) doctors, 9\% nurses and $4 \%$ technicians had adequate awareness level regarding PEP. Fairly adequate level of awareness was $62 \%, 57 \%$ and 50\% among doctors, nurses and technicians respectively. Twenty percent (19.6\%) doctors, 34\% nurses and 46\% technicians were found to have inadequate awareness level regarding PEP. The difference between adequate awareness level among doctor Vs. nurses and doctor Vs. technicians were significant $\quad(\mathrm{p}<0.05)$ (Table: 2)

Out of 250 doctors $16.8 \%$ had experienced one incident of NSI in a year, $13 \%$ had two incidents and $7.6 \%$ had more than two incident in a year. In case of nursing professionals, $32 \%$ had NSI once in a year and $8 \%$ had it twice in a year and $11 \%$ had NSI more than twice in a year. Out of 50 technicians $14 \%$ had NSI once in a year, $26 \%$ had twice in a year and $0 \%$ had more than twice in a year. So the incidence rate of NSI among doctors, nurses and technicians is $38 \%, 51 \%$ and $40 \%$ respectively. Overall incidence rate of NSI among HCWs is $41.5 \%$. (Table: 3 )

The mean of NSI/HCW/year is highest $(0.81)$ in nurses followed by doctors $(0.67)$ and followed by technicians (0.66). The difference between these three groups (doctors, nurses \& technicians) is not significant $(\mathrm{P}>0.05)$. The overall mean of $\mathrm{NSI} / \mathrm{HCW} / \mathrm{Year}$ is 0.71 .

The Obstetrics \& Gynaecology department had highest (mean $=0.93$ ) number of NSI followed by pediatrics (mean $=0.74)$ followed by surgery (mean $=0.68$ ). Though the difference mean of NSI among various department is not significant $(\mathrm{P}<0.05)$. [Fig 1]

Out of 165 NSI among doctors only $14.5 \%$ were reported and out of 81 NSI among nurses only $9.8 \%$ were reported and out of 33 NSI among technicians only 3\% were reported. Over all reported NSI is $11.8 \%$.

NSI is an important issue to be addressed in HCWs. Preventive approach towards NSI is the only effective tool as 'advice after injury is like medicine after death'. Therefore, HCWs must have adequate knowledge 
regarding various causes \& risks of NSI, safe handling of sharps and what to do if such incidents occur.

In our study $41.5 \% \mathrm{HCW}$ gave a history of NSI in last one year, which is a major issue to be concerned. Regional estimates of the annual incidence of sharp injuries shows that the mean number of sharp injuries/HCW/year is 2.27 for southeast Asia $\mathrm{D}$ region (Bangladesh, India, Myanmar, Nepal etc), 0.18 for America A (Canada, USA etc) region and 4.68 for Eastern Mediterranean D regions (Pakistan, Somalia, Sudan) (Prüss-Üstün, Annette, 2005) In the present study, mean NSI among HCW is low $(0.71 / \mathrm{HCW} /$ year $)$ compared to southeast $\mathrm{D}$ region. The mean NSI was highest in nurses (0.81), followed by doctors (0.67) and technicians (0.66), which is statistically found to be insignificant $(\mathrm{P}>0.05)$ among the HCWs. Most of the studies done worldwide reported that NSI were more common in nursing professionals. In USA, nurses accounted for $40 \%$ of the total victims of NSI. Similarly Muralidhar et al., (New Delhi, 2010), reported that $80.1 \%$ HCWs gave a history of NSI , where nurses had the highest number of injury (100\%). This may be because of their more frequent involvement in procedures that carries higher risk of injury like administration of injections \& other invasive procedures.

The incidence rate of NSI $(41.5 \%)$ in our study was found to be low compared to other regional studies. Study conducted by Sharma et al., (Delhi, 2010) and Ashat et al., (Chandigarh, 2011) reported incidence rate of NSI to be $79.5 \%$ \& 68.2 respectively. (Sharma et al., 2010) Despite taking all precautions, NSI incidents may occur. In order to deal with such incidences and to protect the HCWs, every hospital must have the facility of post exposure prophylaxis (PEP) for HIV and HBV infections. All the
HCWs must be aware about the procedures to be followed after NSI to avail the facility of PEP.

All the NSI must be reported to the concern higher authorities but under reporting is a worldwide phenomenon. In our present study NSI was not reported in $88.18 \%$ cases. The magnitude of under reporting of NSI in published studies ranged from $40 \%$ to $90 \%$. The major reasons for not reporting NSI by HCWs are considering source as non infectious, insignificant exposure, too busy to report, already immunized with Hepatitis $\mathrm{B}$, not knowing how to report and thinking that outcome remain unchanged after reporting. (Singru et al., 2008)

Our study found that the mean NSI among HCWs was highest in the Obstetrics \& Gynaecology department (0.93/HCW/Year) followed by pediatrics $(0.74 / \mathrm{HCW} /$ Year $) \&$ Surgery (0.68/HCW/Year). Similar result was also reported by Salehi et al (Afganistan, 2010) where the incidence rates was higher in Obs \& Gynacology department compared to Padiatrics department. Sharma A et al., (New Delhi, 2012) mentioned greater prevalence of NSI in Medicine Department followed by Surgery and Obstetrics \& Gynaecology. Another study in Mumbai showed the accidental injuries among surgery residents was 3 times as compared to Medicine residents. In our study, the incidence rate of NSI is directly related to the amount of workload in the department. The department of Obstetrics \& Gynaecology, LHMC and associated hospital caters to a huge population in central as well as peripheral part of Delhi with 370 bed strength capacity. Approximately 40-50 deliveries per day are being conducted. Similarly pediatrics department has a separate hospital with 375 bed strength and bed occupancy rare per month is around $130 \%-150 \%$. Considering 
these facts, the reason for high NSIs may be due to less attention and time given by the HCWs to adhere to the safe needle handling practices due to more work load. Overall $90.75 \%$ HCWs were aware of NSI. Awareness regarding NSI is inadequate among 22\% technicians, $14 \%$ nurses and $4.80 \%$ doctors. In the present study correct knowledge regarding various risk factors of NSI was $89 \%$ among the HCWs and 59\% HCWs knew the rate of transmission of HBV, HIV \& HCV after NSI. Similar study conducted by Vaz et al., (West Indies, 2010) reported that majority of the HCWs (84\%) identified HIV as a risk of NSI followed by Hepatitis (73\%). (Vaz et al., 2010)

Table.1 Overall awareness regarding NSI

\begin{tabular}{|l|l|l|l|l|l|l|l|l|l|}
\hline \multirow{2}{*}{$\begin{array}{l}\text { Awareness } \\
\text { level } \\
\text { NSI }\end{array}$} & \multicolumn{2}{|l|}{ Doctor(n=250) } & \multicolumn{2}{l|}{ Nurse(n=100) } & \multicolumn{2}{l|}{ Technician(n=50) } & \multicolumn{2}{l|}{ p-value } \\
\cline { 2 - 11 } & No. & $\%$ & No. & $\%$ & No. & $\%$ & $\begin{array}{l}\text { Doctor } \\
\text { Vs. } \\
\text { Nurse }\end{array}$ & $\begin{array}{l}\text { Doctor Vs. } \\
\text { Technician }\end{array}$ & $\begin{array}{l}\text { Nurse Vs. } \\
\text { Technician }\end{array}$ \\
\hline inadequate & 12 & $4.80 \%$ & 14 & $14.00 \%$ & 11 & $22.00 \%$ & 0.002 & $<0.001$ & 0.108 \\
\hline $\begin{array}{l}\text { fairly } \\
\text { adequate }\end{array}$ & 141 & $56.40 \%$ & 63 & $63.00 \%$ & 35 & $70.00 \%$ & 0.129 & 0.037 & 0.198 \\
\hline adequate & 97 & $38.80 \%$ & 23 & $23.00 \%$ & 4 & $8.00 \%$ & 0.002 & $<0.001$ & 0.012 \\
\hline
\end{tabular}

Table.2 Overall awareness regarding PEP

\begin{tabular}{|l|c|c|c|c|c|c|c|c|c|}
\hline \multirow{2}{*}{$\begin{array}{l}\text { Awareness } \\
\text { level } \\
\text { PEP }\end{array}$} & \multicolumn{2}{|c|}{ Doctor(n=250) } & \multicolumn{2}{|c|}{ Nurse(n=100) } & \multicolumn{2}{c|}{ Technician(n=50) } & \multicolumn{3}{c|}{ p-value } \\
\cline { 2 - 10 } & No. & $\%$ & No. & $\%$ & No. & $\%$ & $\begin{array}{c}\text { Doctor } \\
\text { Vs. } \\
\text { Nurse }\end{array}$ & $\begin{array}{l}\text { Doctor Vs. } \\
\text { Technician }\end{array}$ & $\begin{array}{c}\text { Nurse Vs. } \\
\text { Technician }\end{array}$ \\
\hline inadequate & 49 & $19.60 \%$ & 34 & $34.00 \%$ & 23 & $46.00 \%$ & 0.002 & 0.000 & 0.077 \\
\hline $\begin{array}{l}\text { fairly } \\
\text { adequate }\end{array}$ & 155 & $62.00 \%$ & 57 & $57.00 \%$ & 25 & $50.00 \%$ & 0.194 & 0.057 & 0.208 \\
\hline adequate & 46 & $18.40 \%$ & 9 & $9.00 \%$ & 2 & $4.00 \%$ & 0.015 & 0.006 & 0.134 \\
\hline
\end{tabular}

Table.3 Incidents of NSI among HCWs

\begin{tabular}{|l|c|c|c|c|c|c|}
\hline \multirow{2}{*}{$\begin{array}{l}\text { frequency } \\
\text { of NSI }\end{array}$} & \multicolumn{2}{|c|}{ Doctors (n=250) } & \multicolumn{2}{c|}{ Nurse( n=100) } & \multicolumn{2}{c|}{ Technician( n=50) } \\
\cline { 2 - 7 } & $\begin{array}{c}\text { No. of doctors } \\
\text { who had NSI }\end{array}$ & $\%$ & $\begin{array}{c}\text { No. of } \\
\text { nurses who } \\
\text { had NSI }\end{array}$ & $\%$ & $\begin{array}{c}\text { No. of } \\
\text { technicians } \\
\text { who had NSI }\end{array}$ & $\%$ \\
\hline Once & 42 & $16.80 \%$ & 32 & $32.00 \%$ & 7 & $14.00 \%$ \\
\hline Twice & 34 & $13.00 \%$ & 8 & $8.00 \%$ & 13 & $26.00 \%$ \\
\hline $\begin{array}{l}\text { More than } \\
\text { twice }\end{array}$ & 19 & $7.6 \%$ & 11 & $11.00 \%$ & 0 & $0.00 \%$ \\
\hline None & 155 & $62.00 \%$ & 49 & $49.00 \%$ & 30 & $60.00 \%$ \\
\hline
\end{tabular}


Fig.1 Department wise NSI variation:

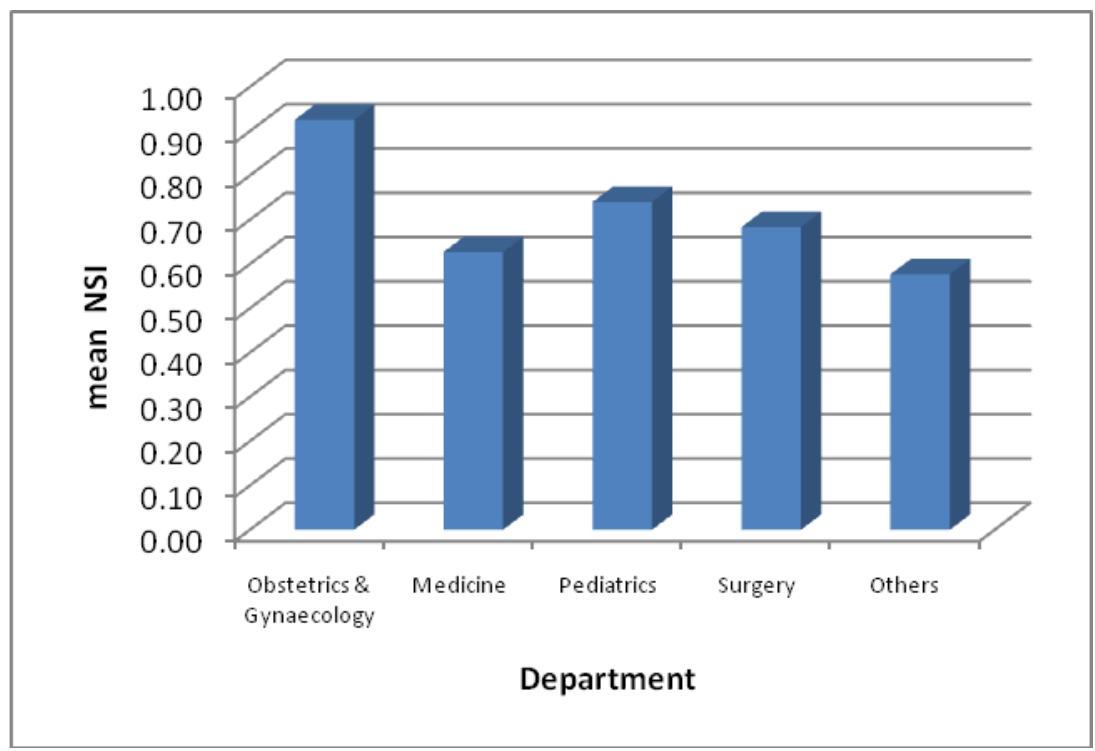

In our study $92 \%$ of the $\mathrm{HCW}$ correctly reported that washing with soap and water is the first step after needle stick injury. Among the HCWs doctors (97.6\%) had highest knowledge followed by nurses $(87 \%)$ \& technicians $(74 \%)$. Various studies in India have reported, HCWs giving the correct response regarding this varies from $60.8 \%$ to $90 \%$.

While evaluating the causes of NSI, majority of the HCWs mentioned recapping $(75.75 \%)$ followed by injury during transporting needles (12.5\%) and while destroying needles $(8.75 \%)$ as the most common causes of NSI. According to the current guidelines, recapping of needle is a forbidden practice. Despite, recapping are still observed constantly and comparatively more throughout the worldwide.

PEP plays an important role in preventing HIV/HBV infection among the HCWs. Therefore, all the HCWs should be aware of time, duration and the facility of PEP in their respective hospitals. In the present study the overall awareness about PEP among the HCWs found to be $73.5 \%$. A much lower awareness (27\%) regarding PEP was reported by Ashat et al., (Chandigarh, 2011) in comparison to the present study (73.5\%). (Ashat et al., 2011)

PEP should be started within 2 hours of NSI and $67 \% \mathrm{HCWs}$ in the present study were aware about this fact. Saini et al., (Maharashtra, 2011) and Mukharjee et al., (West Bengal, 2013), reported the percentage of HCWS who knew that PEP should be initiated within 2 hours of injury was $89 \%$ and $68.5 \%$ respectively. (Mukherjee et al., 2013)

Knowledge regarding how to avail PEP in our hospital was known by overall $56.25 \%$ HCWs which was highest among nurses (68\%), followed by doctors $(53.2 \%) \&$ technicians $(48 \%)$. Similar study conducted in Safdarjang hospital, New Delhi and West Bengal reported the percentage of $\mathrm{HCWs}$ who knew about PEP facility in their hospital was less than $50 \%$ \& $66 \%$ respectively.

In our study $44 \% \mathrm{HCWs}$ convey the correct knowledge about the duration of PEP. 
Similar finding (46.9\%) was noted by Mukherjee S et al., (West Bengal, 2013) in their study.

In conclusion, NSI is considered to be one of the important health hazards that the health care workers face daily during their work in the hospital. In the present study we have found the incidence of NSI among the HCWs of Lady Hardinge Medical College \& Associated Hospital to be $41.5 \%$ and the mean NSI was $0.71 / \mathrm{HCW} / y e a r$. Considering this fact and other findings of the present study, it can be stressed upon here that all the hospitals must start a multistage approach for prevention and surveillance of NSI and thereby preventing the HCWs from acquiring a wide range of blood borne infections. Regular training programmes for all categories of $\mathrm{HCWs}$ regarding various aspects standard precautions and NSI will develop a more responsible attitude among the HCWs towards prevention of NSI. Furthermore, it is the sole responsibility of any healthcare organization to motivate the HCWs to report the NSI cases immediately to the higher authorities for optimal utilization of PEP facility provided to them.

\section{References}

Ashat, M., Bhatia, V., Puri, S., Thakare, M., Koushal, V. 2011. Needle Stick Injury and HIV among health care workers in north India. Int. J. Med. Sci., 65(9): 371-378.

Camilla Rodrigues. 2010. Needle stick injuries \& the health care worker - the time to act is now. Indian J. Med. Res., 131: 384-386.

Centers for Disease Control and prevention: Stop stick campaign- NIOSH. Available from: http://www.cdc.gov/niosh/stopsticks/s harpsinjuries.html. (Accessed on $27^{\text {th }}$ March 2015)
Foley, M., Leyden, A.M. 2003. American Nurses Association Independent Study Module, Needle Stick Safety and Prevention. Available from: <www.nursingworld.org/rnce>. [Accessed 31 ${ }^{\mathrm{st}}$ March 2015.]

Gupta, E., Katiyar, V. 2013. Study on Needle Stick Injuries, among nurses of a tertiary care hospital of Assam. Indian J. Appl. Res.,3(7).

Kotwal, A., Taneja, D.K. 2010. Health Care Workers and Universal Precautions: Perceptions and Determinants of Noncompliance. Indian J. Community Med., 35(4): 526-528.

Mihir, G., Patel, P., Nayak, S., Mehta, H.K., Shah, R., Devmurari, D. et al. 2010. Needle stick and sharp injuries among health care providers at cardiology institute, Ahmedabad. Natl. J. Community Med., 1(2): 114.

Mukherjee, S., Bhattacharyya, A., Sarkar, B.S., Goswami, D.N., Ghosh, S., Samanta, A. 2013. Knowledge and Practice of Standard Precautions and Awareness Regarding Post-Exposure Prophylaxis for HIV among Interns of a Medical College in West Bengal, India. Oman Med. J., 28(2): 141-145.

Muralidhar, S., Singh, P.K., Jain, R.K., Malhotra, M., Bala, M. 2010. Needle stick injuries among health care workers in a tertiary care hospital of India. Indian J. Med. Res., 131: 405410.

Prüss-Üstün, Annette, Elisabetta, R., Yvan, H. 2005. Estimation of the global burden of disease attributable to contaminated sharps injuries among health-care workers. Am. J. Ind. Med., 48(6): 482-490.

Rele, M., Mathur, M., Turbadkar, D. 2002. Risk of needle stick injuries in health care workers. Indian J. Med. Microbiol., 20(4): 206-207. 
Saini, R. 2011. Knowledge and awareness of needle stick injury among students of Rural Dental College, Maharashtra. India. Ann. Nigerian Med., 5(1): 1214.

Salehi, A.S., Garner, P. 2010. Occupational injury history and universal precautions awareness: a survey in Kabul hospital staff. BMC Infect. Dis., 30(10): 19.

Sharma, A., Gur, R., Bhalla, P. 2012. Study on prevalence of Needle Stick Injury among health care workers in a tertiary care hospital in New Delhi. Int. J. Public health, 56(1): 101-103.

Sharma, R., Rasanis, S.K., Verna, A., Singh, S. 2010. Study of prevalence and Response to Needle Stick Injuries among Health Care Workers in a tertiary care Hospital in Delhi, India. Indian J. Community Med., 35(1): 7477.

Singru, S.A., Banerjee, A. 2008. Occupational exposure to blood and body fluids among Health care workers in a teaching hospital in Mumbai, India. Indian J. Community Med., 33: 26-30.

Vaz, K., McGrowder, D., Alexander-Lindo, R., Gordon, L., Brown, P., Irving, R. 2010. Knowledge, Awareness and Compliance with Universal Precautions among Health Care Workers at the University Hospital of the West Indies, Jamaica. Int. J. occup. Environ. Med., 1(4): 171-81.

\section{How to cite this article:}

Debbarma, M., S. Gogoi, M. Jais, P.Gupta, P. Sharma and Kaur, R. 2016. Incidence and Comparative Awareness regarding Needle Stick Injuries among Health Care Workers: A Tertiary Healthcare based Study from North India. Int.J.Curr.Microbiol.App.Sci. 5(6): 763-770. doi: http://dx.doi.org/10.20546/ijcmas.2016.506.084 